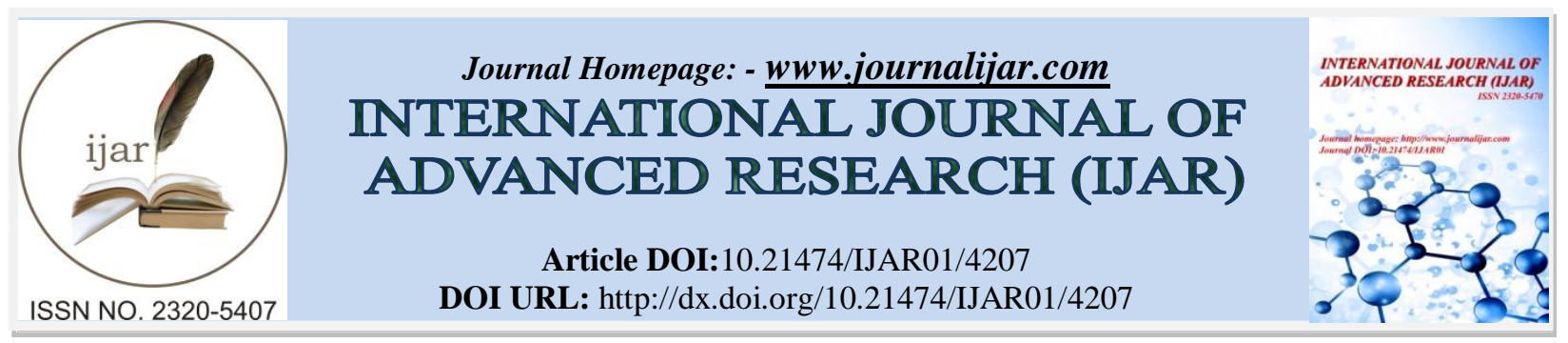

RESEARCH ARTICLE

\title{
AFGHANISTAN PUBLIC HEALTH FACILITIES STAFFS' JOB SATISFACTION AND FACTORS AFFECTING THE JOB SATISFACTION.
}

M.Naim.Rassa.

Jodhpur School of Public Health (JSPH) Maulana Azad University Jodhpur, India.

\section{Manuscript Info}

Manuscript History

Received: 17 March 2017

Final Accepted: 15 April 2017

Published: May 2017

\section{Abstract}

Rational: The ultimate goal of health sector is to provide quality services. Generally, healthcare services are affected by many factors and satisfaction of human resources is a vital component in delivery of quality health services. Therefore an understanding of health services providers' satisfaction is necessary to find the gaps and accordingly address them.

Objective: The objectives of the paper was to identify the level of staff satisfaction and the factors affecting the job satisfaction in Public Health facilities of Afghanistan.

Method: A Cross-sectional study is conducted in three provinces of Afghanistan. The sample size was 451 public health workers and data was collected from all the staff of the selected health facilities of Logar, Badakhshan and Daikundi provinces.

Population: The population of the study were the staff of all health facilities in the selected districts and provinces of Afghanistan which were 451 participants.

Time Frame: The study took 32 weeks from the start to the preparation of the first draft report.

Results: 52.8\% (238) of the total respondents (451) reported that they are dissatisfied and $47.2 \%$ (213) respondents reported that they are satisfied. Moreover; the factors resulting dissatisfaction includes low salary, low benefit, work load, no supportive supervision, no recognition, insecurity, no risk benefits, no required living facilities (delocalized staff), no training in use of new medical equipment and insufficient professional trainings.

Conclusion and Recommendation:Job satisfaction of health workers is an essential part for ensuring high quality service delivery. The finding of the study indicates low salary package, low benefits, no supportive supervision, insufficient professional trainings and recognition are of more important factors of dissatisfaction; therefore interventions should be carried out to increase levels of job satisfaction among public health professionals to obtain higher level of health worker satisfaction and accordingly ensure high quality service delivery. 


\section{Acknowledgements:-}

I, the author of this paper would like to express my sincere gratitude to my professors atJodhpur School of Public Health (JSPH), Maulana Azad University, Dr LatikaNath Sinha, Dr Nitin Joshi, Dr PramilaVivek, who taught me how to conduct a research and provided me with valuable comments on my work.Besides I gratefully acknowledge the contribution of Dr Nasir Ahmad Hamid the operation director for care of Afghan Family Organizationand my co-guide. Furthermore I acknowledge the support of Dr Khalil Ahmad Mohmand The executive director for Social and Health Development program (SHDP) who reviewed the report and provided constructive feedback.

I also would like to thank the team (supervisors, Data collectors and Data entry officers) who participated in this work and finally I would like to thank all staff of health facilities in Badakhshan, Logar and Daikundiprovinces, who gave their time and participated in this study.

I hope this research will contribute to the enhancement of quality of health service delivery in Afghanistan.

\section{Rationale and Background:-}

Efforts to improve national and international health indicators, including the Millennium Development Goals (MDG), are limited by the quantity and quality of human resources for health (HRH), available to implement lifesaving health-care service (Bailey RJ \& Dal Poz M, 2010). But as general understanding health care services deliveries are affected by many factors such as but not limited to human resources, health services delivery system, availability of pharmaceutical, required medical and non-medical equipment, supplies and health infra-structures. Among these factors the human resources is a vital component in delivering health services. Job satisfaction of the health workers is highly important in building up employee motivation and efficiency as higher job satisfaction determine better employee performance and higher level of patients' satisfaction. Besides Job dissatisfaction resulting low quality performancewhich will then result increase in prevalence of several diseases, disease gets chronic and finally increase in morbidity and mortality may occur. Timothy A. Judge (2001) in the article under the title "The Job Satisfaction-Job Performance Relationship" concludes that the mean true correlationbetween job satisfaction and job performance is moderate in magnitude (.30) and distinguishable from zero.McKenna (2012) stated that most researchers agreed that job satisfaction is closely related to behaviors and attitudes at workbesides job satisfaction is a multifaceted concept related to employee's attitude and feelings towards his or her job (Mullins, 2005).Sy, Tram and O'Hara (2006) state that employee productivity depends on the amount of time an individual is physicallypresent at a job and also the degree to which he or she is "mentally present" or efficiently functioning while present at a job. Hence, companies must address both of these issues in order to maintain high worker productivity. Flynn (2005) states that if service employees are satisfied, the latter will in return tend to be committed to making an extra effort to the organization as a means of reciprocity for their employer leading to a higher level of service quality.Furthermore several other studies also indicate that there is positive relationship between Job satisfaction and performancethat can be referred under literature review and in this study we do not intend to study the relationship between job satisfaction and performance as from the literature review it is clear that the job satisfaction and performance has positive relationship.

So considering the importance of the statement that job satisfaction has effect on the performance and the quality of the performance, an understanding of health services providers' satisfaction was necessary to find the gaps and accordingly address them for ensuring quality health services in Afghanistan. Apparently Afghanistan looks to have many serious shortfalls in terms of human resources for health. The workers within the public health facilities face numerous issues that grossly affect the level of job satisfaction and health care service deliveries. As every health system is expected to ensure quality health care and to do so health system workforce should be satisfied so that they deliver quality health care; Subsequently so far no study was conducted in this regards in Afghanistan to find the degree or level of health service providers' satisfaction; which affect the quality of health services deliveries and population health as wholetherefore such studywas needed to be performed.Thestudy intended to; find the rate of health facilities staff satisfaction and accordingly the factors that influence the satisfaction or dissatisfaction of the health facilities staff, share the result with BPHS Implementer and other stake holders; acquire their attention in this important aspect of health system (Human Resources)and finally through addressing the existing issues to ensure quality health care services delivery though health facilities staff to the clients in Afghanistan. 


\section{Literature Review:-}

Human resources in health system is the back bone for the provision of quality health care for the population, in spite of this fact there is no literature in the areas related to rate of satisfaction and the factors affecting job satisfaction of health providers in Afghanistan. The only study which is conducted in Afghanistan was a study under the title "Job satisfaction and retention of health-care providers in Afghanistan and Malawi" in which the author Linda, F. et al concluded that the construction of concepts of health-care worker satisfaction and intention to stay on the job are highly dependent on the local context. Although health-care workers in both Afghanistan and Malawi reported satisfaction with their jobs, the predictors of satisfaction, and the extent to which those predictors explained variations in job satisfaction and intention to stay on the job, differed substantially.

David, H.P et al. (2010) states that World Health Organization (WHO), and the Global Health Workforce Alliance (GHWA) have been focusing attention on health workers, particularly on the pervasive problems with staffing shortages, poor job conditions, low remuneration, and extensive migration. As the backbone of the health system, health workers usually account for the largest share of public expenditures on health. The presence of high-quality, motivated staff is a key aspect of health system performance, but also one of the most difficult inputs to ensure. Health worker job satisfaction, which is generally defined as 'the attitude towards one's work and the related emotions, beliefs, and behaviour', results from complex interactions between on-the-job experience, organizational environment, and motivation. Job satisfaction is inextricably linked to motivation, and both involve cognitive, affective, and behavioural processes, with worker motivation commonly understood as the reason why workers behave as they do towards achieving personal and organizational goals.

Job satisfaction is one of the most studied areas in organizational psychology and is generally defined as "the attitudes and feelings people have about their job. Positive and favorable attitudes towards the job indicate job satisfaction, and negative and unfavorable attitudes towards the job indicate job dissatisfaction" (Armstrong, 2008).

Amos, Ristow, et al. (2008) postulate that employees experiencing high satisfaction levels contribute to organizational commitment, job involvement, improved physical and mental health, and improved quality of life both on and off the job.

Job satisfaction is an issue that affects the lives of all workers including health professionals and is also a factor that determines whether an employee will remain in a position or seek work elsewhere. Furthermore, job satisfaction can influence the quality of work produce (AlemshetYami et al, 2011).

McKenna (2012) stated that most researchers agreed that job satisfaction is closely related to behaviours and attitudes at work besides job satisfaction is a multifaceted concept related to employee's attitude and feelings towards his or her job (Mullins, 2005).

Sy, Tram and O'Hara (2006) state that employee productivity depends on the amount of time an individual is physically present at a job and also the degree to which he or she is "mentally present" or efficiently functioning while present at a job. Hence, companies must address both of these issues in order to maintain high worker productivity.

Newman et al.'s (2001) chain outlines a clear interrelationship between employee satisfaction, the quality of care, and patient satisfaction.

Atkins et al., (1996) showed that employee dissatisfaction negatively impacts the quality of care and ultimately has an adverse effect on patient loyalty and in turn hospital profitability. Quality improvement initiatives were shown to have a positive correlation with employee satisfaction as well as client satisfaction in a study of Swedish healthcare (Kammerlind, et al, 2004). Health care employee morale also demonstrates a strong correlation with patient satisfaction scores, showing that the lack of commitment and engagement have far-reaching impacts on more than just employee turnover (JCAHO 2005).

Katja, G et al. (2015) in a study under the title Working Atmosphere and Job Satisfaction of Health Care Staff in Kenya states that Job satisfaction and working atmosphere are important indicators for recruitment and retention of health care staff but also for the provision of good quality of care. 
Ramesh Kumar et al. (2013) in a study under the title "Job satisfaction among public health professionals working in public sector: a cross sectional study from Pakistan" concludes that our study documented a relatively low level of overall satisfaction among workers in public sectorhealth care organizations. Considering the factors responsible for this state of affairs, urgent and concrete strategiesmust be developed to address the concerns of public health professionals as they represent a highly sensitivedomain of health system of Pakistan. Improving the overall work environment, review of job descriptions and betterremuneration might bring about a positive change.

Finally from all the mentioned literature and considering the fact that healthcare is crucial service industry that has significant effects for facilitating productivity increases, supporting the population's general wellbeing and enabling them to pursue a more meaningful life (Siddiqui and khandakar, 2007) we can conclude that job satisfaction and performance has positive relationship, Job satisfaction is the degree of favorableness with which the employees view their work. It is an issue that affects the lives of all workers including health professionals, and patient, it is an issue that influence patient satisfaction, andit is also a factor that determines whether an employee will remain in a position or seek work elsewhere. Furthermore, job satisfaction can influence the quality of work produced. Therefore knowing the level of staff satisfaction at health facility level and finding up the factors influencing staff job satisfaction at health facilities level is essential to ensure Human resources and health service delivery aspects of the health system.

\section{Objectives:-}

The major objective of this study was to identify Afghanistan Public health facilities staffs' satisfaction and factors affecting the job satisfaction, the gaps within the human resource aspect of the health system and accordingly address them through sharing of the results with BPHS\& EPHS implementer and other stakeholders to acquire their attention in this important aspect of health system.

The specific objective of this study was:

1. Finding the rate of health facilities staff satisfaction.

2. Finding the factors that influence the satisfaction or dissatisfaction of the health facilities staff.

3. Stating key recommendation to BPHS/EPHS implementer and other stakeholders.

\section{Study Design:-}

This was a cross-sectional study which is conducted in Afghanistan in order to identify the gaps within the human resource aspect of the health system and outline the rate of Public health facilities staffs' satisfaction, and the factors affecting the job satisfaction. Besides in this study it is ensured that all type of health facilities such as Sub Center (SC) Basic Health Center (BHC) Comprehensive Health Center (CHC), District Hospital (DH), and Provincial Hospital (PH) are included in the study.

\section{Target Respondents/participant:-}

The research population or the sampling frame wasall the staff of health facilities from the selected health facilities.

\section{Sample size:-}

In order to reach to the sample size who were the target participants of the study, multi stage sampling is used.

\section{Stage 1: Selection of Provinces:-}

For selection of the provinces which was the primary sampling unit, from the 34 provinces of Afghanistan was done by listing all the regions of Afghanistan with their provinces. As per Afghanistan Mortality Survey (AMS, 2010) Afghanistan is divided in to eight regions; Table 1 below describes the list of all the regions and provinces of Afghanistan. 
Table 1

List of Regions and Provinces OF Afghanistan

\begin{tabular}{|c|c|c|c|c|}
\hline No & Provinces & $\begin{array}{l}\text { Province } \\
\text { Code }\end{array}$ & Regions & $\begin{array}{c}\text { Popultaion As } \\
\text { per CSO }\end{array}$ \\
\hline 1 & Balkh & 21 & North Region & $1,245,100$ \\
\hline 2 & Faryab & 29 & North Region & 948,000 \\
\hline 3 & Jawzjan & 28 & North Region & 512,100 \\
\hline 4 & Samangan & 20 & North Region & 368,800 \\
\hline 5 & Sari Pul & 22 & North Region & 532,000 \\
\hline 6 & Baghlan & 9 & North Eastern region & 863,700 \\
\hline 7 & Kunduz & 19 & North Eastern region & 953,800 \\
\hline 8 & Takhar & 18 & North Eastern region & 933,700 \\
\hline 9 & Badakhshan & 17 & North Eastern region & 904,700 \\
\hline 10 & Badghis & 31 & Western region & 471,900 \\
\hline 11 & Farah & 33 & Western region & 482,400 \\
\hline 12 & Ghor & 23 & Western region & 657,200 \\
\hline 13 & Herat & 32 & Western region & $1,780,000$ \\
\hline 14 & Bamyan & 10 & Central Highland Region & 425,500 \\
\hline 15 & Daykundi & 24 & Central Highland Region & 438,500 \\
\hline 16 & Kabul & 1 & Capital & $3,950,300$ \\
\hline 17 & Logar & 5 & Capital & 373,100 \\
\hline 18 & Parwan & 3 & Capital & 631,600 \\
\hline 19 & Kapisa & 2 & Capital & 419,800 \\
\hline 20 & Panjsheer & 8 & Capital & 146,100 \\
\hline 21 & Maydan Wardak & 4 & Capital & 567,600 \\
\hline 22 & Nimroz & 34 & Southern Region & 156,600 \\
\hline 23 & Helman & 30 & Southern Region & 879,500 \\
\hline 24 & Kandahar & 27 & Southern Region & $1,151,100$ \\
\hline 25 & Zabul & 26 & Southern Region & 289,300 \\
\hline 26 & Uruzgan & 25 & Southern Region & 333,500 \\
\hline 27 & Ghazni & 11 & Southern Region & $1,168,800$ \\
\hline 28 & Paktia & 13 & South Eastern Region & 525,000 \\
\hline 29 & Khost & 14 & South Eastern Region & 546,800 \\
\hline 30 & Paktika & 12 & South Eastern Region & 413,800 \\
\hline 31 & Nuristan & 16 & Eastern region & 140,900 \\
\hline 32 & Laghman & 7 & Eastern region & 424,100 \\
\hline 33 & Kunar & 15 & Eastern region & 428,800 \\
\hline 34 & Nangarhar & 6 & Eastern region & $1,436,000$ \\
\hline
\end{tabular}

Then three provinces from all regions are selected using Simple Random Sampling;

Table 2:- Represents the list of the selected provinces.

Table 2

List of Selected provinces

\begin{tabular}{|c|c|c|c|c|}
\hline No & Provinces & $\begin{array}{l}\text { Province } \\
\text { Code }\end{array}$ & Regions & $\begin{array}{c}\text { Popultaion As } \\
\text { per CSO }\end{array}$ \\
\hline 1 & Badakhshan & 17 & North Eastern region & 904,700 \\
\hline 2 & Daykundi & 24 & Central Highland Region & 438,500 \\
\hline 3 & Logar & 5 & Capital & 373,100 \\
\hline
\end{tabular}




\section{Stage 2: Selection of Districts:-}

Selection of the districts, which is the secondary sampling unit from the selected provinces are made applying Probability Proportional to Size (PPS). One district from each province is selected. Beside tocorrect for the difference in design, a design effectof 2 is considered and accordingly 2 districts from each province are selected for the study; Table 3 describe the selected districts within each province .

Table 3.

List of Selected District From Selected Provinces of Afghanistan

\begin{tabular}{|c|c|c|c|c|c|}
\hline No & District & District Code & Province & Region & Population \\
\hline 1 & Argo & 1,515 & Badakhshan & North Eastern region & 76,200 \\
\hline 2 & Kishm & 1,502 & Badakhshan & North Eastern region & 78,600 \\
\hline 3 & Daykundi Center (Nili) & 2,101 & Daykundi & Central Highland Region & 39,600 \\
\hline 4 & Khedir & 2,105 & Daykundi & Central Highland Region & 45,300 \\
\hline 5 & Baraki Barak & 503 & Logar & Capital & 85,200 \\
\hline 6 & Mohammad Agha & 505 & Logar & Capital & 73,400 \\
\hline
\end{tabular}

Stage 3: Selection of Health facilities:-

For selection of health facilities, Random sampling is not performed, and it is decide to include all the health facilities in the study. So by completing the process atotal of 451 health facilities staff (both Male \& female) were the study participants while the approximate number of participants were 404 as per the table below in the research proposal: The reason behind the increase in number of participants were that in some health facilities the number of the staff were more than the standard staffing pattern of BPHS.

Table 4.

Calculation of Study Participants

\begin{tabular}{|c|c|c|c|c|c|c|c|c|r|r|}
\hline \multicolumn{4}{|c|}{ No of HFs } & \multicolumn{5}{|c|}{ Aproxmate No of Staff } & of \\
Partcipant
\end{tabular}

\section{Inclusions Criteria:-}

1. The Districts within the selected provinces which were secure.

2. All type of Health facilities located in the selected districts of the province.

3. All the staff of the public health facility including the medical specialists, doctors, nurses, midwives, other health worker (Vaccinators, Pharmacy staff, CHSs, lab technicians) and other clinical support staff

\section{Exclusion Criteria:-}

4. Insecurity of the district and health facilities

5. Non accessibility

6. Closed health facilities

Duration of the study:-

This study took a period of 32 weeks as per the below timeline. 


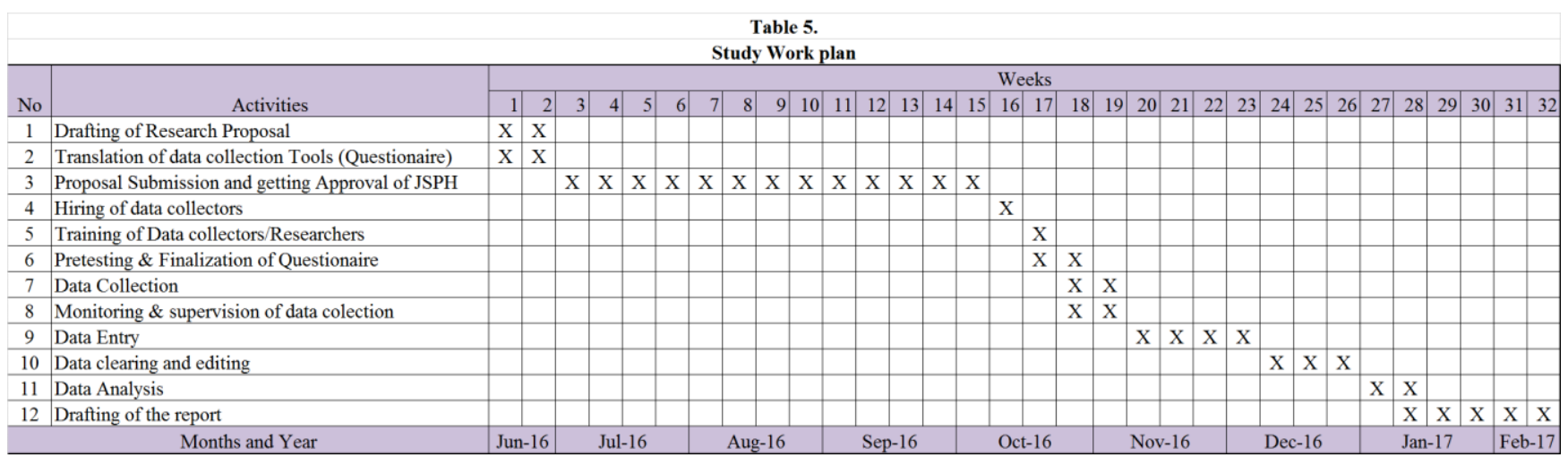

\section{Research Methodology:-}

A cross section study is conducted to determine the job satisfaction rate of health providers at public health facilities level and besides to identify the factors affecting job satisfaction. This study is carried out inthree region or provinces of Afghanistan such as the North Eastern, Central Highland, andCapital using multi stage sampling to select the provinces as the primary sampling unit.Then selection of the at least one district from each selected province is done by applying Probability Proportional to Size (PPS), for detail of the selection please refer to design method. After selection of the secondary sampling units; to correct for the difference in design, a design effect of 2 is considered and accordingly 2 districts from each province are selected. The staffs of all health facilities in the selected districts were 451 participants.

\section{Study Tool:-}

Following tool are used:

\section{Health Facility staff Questionnaire:-}

This questionnaire is filled from each staff of health facility both male and female (Refer to Annex I Health Facility staff Questionnaire).

\section{Pilot Testing:-}

Data collection instrument/tool, Health Facilities staff questionnaire, is developed in English. The tool is then translated in to local languages (Dari) and back it is retranslated to English to ensure the quality of translation. A pre-test of the study tools is considered in order to check the tools (questionnaires) and to identify and solve the unforeseen problems before the actual data collection. The pre-test emphasized to improve the translation, check accuracy and adequacy of the questionnaire, and to know the time of the interview for each questionnaire. In addition, participant pre-test at the training room is also ensured.

\section{Training:-}

Three days training is conducted for field researchers and surveyors on the data collection tools, survey method, sampling and piloting. The training is conducted in one batch separately in each province. Necessary training material isprovided to the participants during the training. Different methodologies are used in order to make sure the participants understand the objective of the training such as presentation, flip chart, role play and mapping. The training isprovided in one local language (Dari). In order to ensure the knowledge of participants on the survey tools a reliability testing training is alsotaken from all participants. For two participants in Badakhshan province and one in Logar whose combined score was lower than $90 \%$ additional one day of training is conducted which made them ready to obtain quality data from the field.

\section{Data collection:-}

14 Field researchers collected data from all the health facilities male and female staff. A total of 451 participants are interviewed. To minimize the potential for social desirability bias, the interviewer explained the purpose, confidentiality and anonymity of the study to each provider before seeking consent, after a consent form is signed by each participant (Annex II-Consent Form).Interviewers then conducteda face-to-face meeting with clinical healthcare providers (medical doctors, nurses, midwives, Vaccinators, Pharmacy staff, CHSs, lab technicians and other 
clinical support staff) using a standardized, structured questionnaire. Data collectiontook a period of 2 weeks simultaneously in all provinces and finally after data collection is completed, an excel data base is prepared where all the data from the questionnaires are entered into and then transferred to SPSS for the analysis.

\section{Monitoring and supervision:-}

The process of data collection are monitored and supervised by 3 supervisor and principle investigator during data collection period and at least $10 \%$ of the data are rechecked by principle investigator\& the field supervisors.

\section{Date Analysis:-}

For analyzing purpose all data from the questionnaires are entered into excel base software at the main office. Data are edited and cleaned by principle investigator. I used double data entry mechanism for each filled questionnaire to minimize keypunch errors and ensured the quality of data entered into excel made software. Then the data are transferred to SPSS for further analysis purpose.

\section{Ethical Consideration:-}

This study cannot be the representative of all Afghanistan therefore it did not require MOPH Institutional Review Board (IRB). However, for ethical purpose all data are stored in a safe place and only authorized staff have access to the data bank. The individual information of respondent is kept confidential and not disclosed during the analysis or dissemination phases. Informed consent note in written ((Annex II-Consent Form) were taken from each respondent during the interview and data collection. The respondents are informed about their rights during the study.

\section{Limitations of the study:-}

The limitations of the study at are the following:

1. Budget limitation did not permit this study to be conducted in a wider range, so that it was the representative of all Afghanistan.

2. This study was designed to find out the rate for staff satisfaction and or dissatisfaction in Afghanistan public Health facilities. As such, it provides a snapshot of health worker perspectives at one point in time, and the causal relationships between satisfaction and performance cannot be further delineated in this study. Thus this study did not measure performance of health workers.

3. Like many other studies of health-care worker satisfaction, this analysis is based on cross-sectional rather than longitudinal data and therefore cannot be used to infer causal linkages between satisfaction and performance.Results and Key finding

\section{Demographics of health workers:-}

A total of 451 health worker are interviewed in three provinces of Afghanistan (Badakhshan, Daikundi and Logar), we were able to obtain $100 \%$ response rate from the health care workers at participating facilities andmissing data is zero as described in Table 6 below. 71\% (321) of the participants were male and 29\% (130) female. The respondent were from different type of health facilities (1 Provincial Hospital, PH, 3 District Hospital, DH, 3 Comprehensive Health Center, CHC, 17 Basic Health Center, BHC, 7 Sub Health Center SHC and 1 Mobile Health Team, MHT) and included positions such as doctors, nurses, midwifes, pharmacists, pharmacy technicians, lab technicians, Vaccinators, community health supervisors and supportive staff. For further analysis purpose; all these positions are categorized into 9 categories such as female specialists, male specialists, female MD, male MD, female Nurses, male nurses, midwifes, other health worker (pharmacists, pharmacy technicians, lab technicians) and supportive staff (cook, mechanics, guard and cleaners).

Table 6:-Case Processing Summary

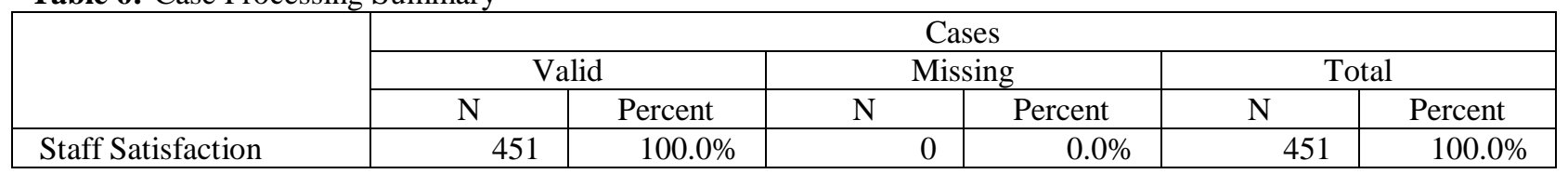


General Status on satisfaction and dissatisfaction:-

The health worker satisfaction Questionnaire was composed of 23 items, and the items are mainly focused on determinants of job satisfaction; for detail please see Annex 3 the summary of the responses by the respondents for each items.

Overall, 52.8\% (238) of the total respondents reported that they are dissatisfied and $47.2 \%$ (213) respondents reported that they are satisfied. Meanwhile among the dissatisfied employees, $70 \%$ were male and $30 \%$ females and among satisfied staff $72 \%$ were male and $28 \%$ were female.

Table 7:- Satisfaction Rate

\begin{tabular}{|c|c|c|c|c|c|}
\hline & \multicolumn{2}{|c|}{ Health Facilities staff } & \multirow[t]{2}{*}{ Total } \\
\hline & & & Yes & No & \\
\hline & \multirow[t]{2}{*}{ Satisfy } & Count & 213 & 238 & 451 \\
\hline & & $\%$ & $47 \%$ & $53 \%$ & $100.0 \%$ \\
\hline & \multirow[t]{2}{*}{ Dissatisfy } & Count & 238 & 213 & 451 \\
\hline & & $\%$ & $52.8 \%$ & $47.2 \%$ & $100.0 \%$ \\
\hline \multirow{2}{*}{\multicolumn{2}{|c|}{ Total }} & Count & 451 & 451 & 902 \\
\hline & & $\%$ & $47 \%$ & $53 \%$ & $100.0 \%$ \\
\hline
\end{tabular}

Figure 1:-Staff Satisfaction rate

\begin{tabular}{|c|c|c|c|c|}
\hline \multicolumn{5}{|c|}{ Staff Satisfaction Rate } \\
\hline 500 & & & 451 & \multirow{11}{*}{$\begin{array}{l}\text { No of staff } \\
\text { Rate }\end{array}$} \\
\hline & & & & \\
\hline 350 & & & & \\
\hline 300 & & & & \\
\hline 250 & 212 & 238 & & \\
\hline 200 & 210 & \multirow{4}{*}{$53 \%$} & & \\
\hline 150 & $47 \%$ & & & \\
\hline 100 & & & & \\
\hline 50 & & & & \\
\hline 0 & & & & \\
\hline & Satisfy & Dissatisfy & Total & \\
\hline
\end{tabular}


Figure 2:-Comparison of Satisfaction between Male and Female

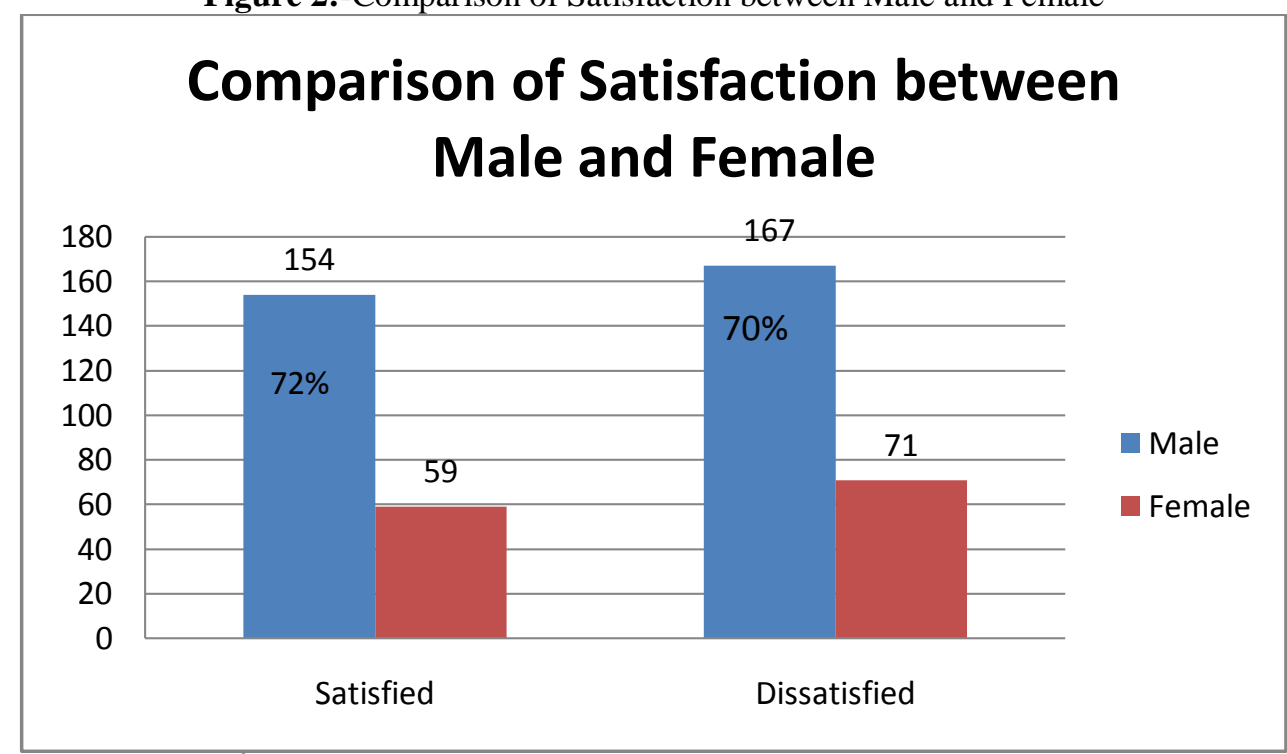

The chi square test result $\left(\chi^{2}(1) 0.249, \mathrm{p}=0.617\right)$ show that there is no significant difference between the level of satisfaction between male and female health workers.

Table 8:- Comparison of Satisfaction between Male and Female

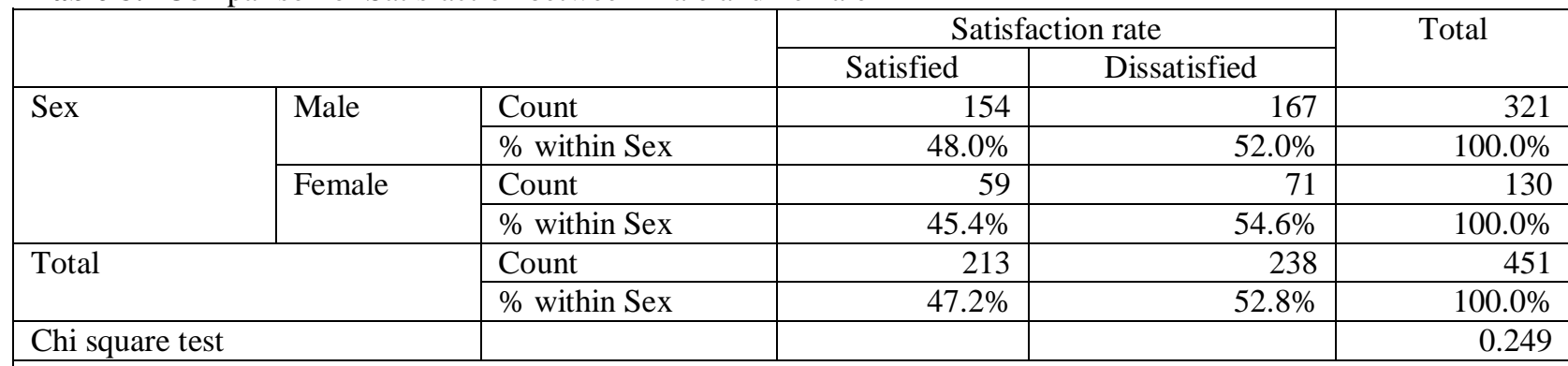

Each subscript letter denotes a subset of Q1Yes1No2 categories whose column proportions do not differ significantly from each other at the .05 level.

As per the analysis made; the factors resulting dissatisfaction includes low salary, low benefit, work load, no supportive supervision, no recognition and other factors such as insecurity, no risk benefits for the staff, no required living facilities (delocalized staff), no training in use of new medical equipment and insufficient professional trainings for which the percentage of each factor is given below and shown in Graph 2 .

1. Salary: From the total of dissatisfied staff (238 respondent) $100 \%$ is reported that their dissatisfaction is due to low salary.

2. Work Environment: From the total of dissatisfied staff (238 respondents) 5.5\% is reported that their dissatisfaction is due to work place environment.

3. Working Time: No figure is detected to show that dissatisfaction is due to inappropriate working time.

4. Benefits: From the total of dissatisfied staff (238 respondent) $94.5 \%$ is reported that their dissatisfaction is due to low benefit.

5. Unavailability of appropriate quantity of pharmaceuticals: No figure is detected to show that dissatisfaction is due to this variable.

6. Support from implementing organization: No figure is detected to show that dissatisfaction is due to this variable.

7. Late Payment of salaries: No figure is detected to show that dissatisfaction is due to this variable.

8. Work load: From the total of dissatisfied staff (238 respondent) $9.2 \%$ is reported that their dissatisfaction is due to Work load. 
9. No Supportive supervision: From the total of dissatisfied staff (238 respondent) $67.2 \%$ is reported that their dissatisfaction is due to shortage of supportive supervision.

10. Other factors: From the total of dissatisfied staff ( 238 respondent) $53.8 \%$ is reported that their dissatisfaction is due to other factors such as insecurity, No risk benefits for the staff, no required living facilities (delocalized staff), no training in use of new medical equipment, and insufficient training.

Figure 3:-Factors Resulting Dissatisfaction

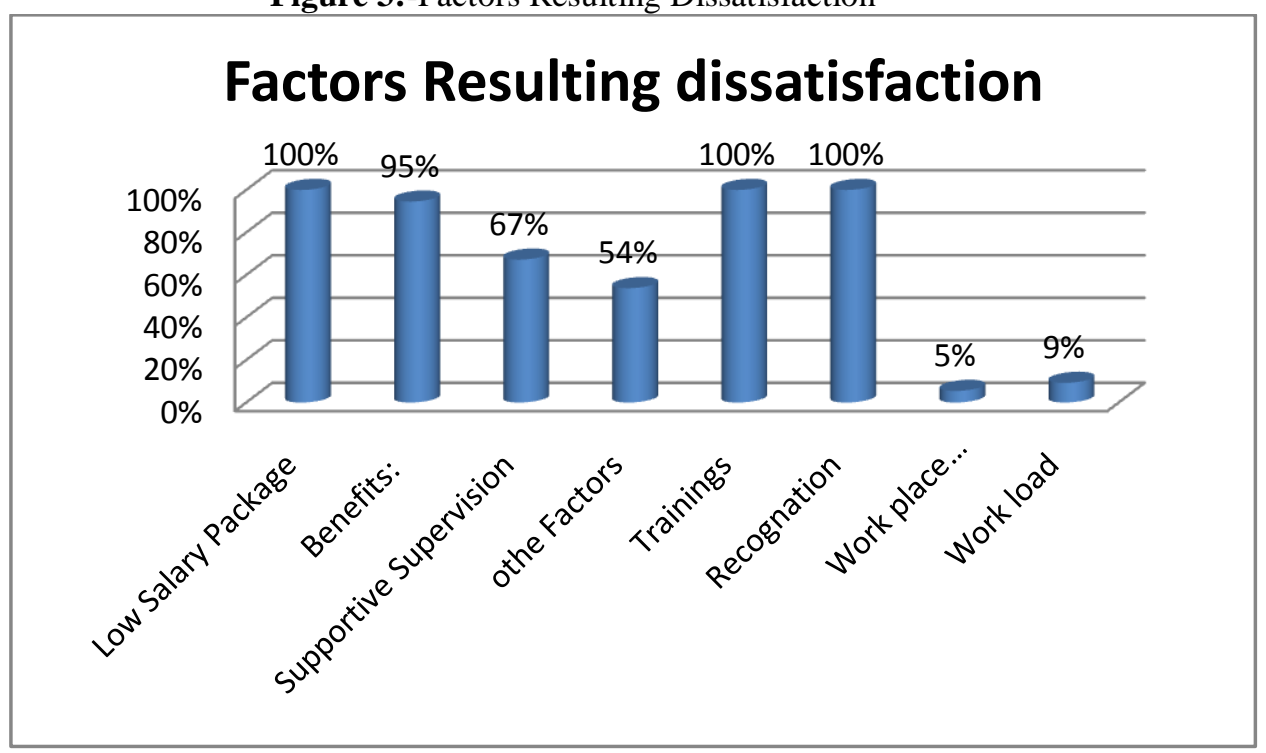

Moreover as per the analysis made; the factors resulting satisfaction includes appropriate salary, work place environment, benefits, Availability of pharmaceutical, Support from implementing NGO, On time payment of salaries, and Supportive supervision for which the percentage of each factor is given below:

1. Salary: From the total of satisfied staff (213 respondent) $85.9 \%$ is reported that their satisfaction is due to salary.

2. Work place environment: From the total of satisfied staff (213 respondent) $91.1 \%$ is reported that their satisfaction is due to appropriate Work place environment.

3. Working Time: No figure is obtained to show that satisfaction is due to this variable.

4. Benefit: From the total of satisfied staff (213 respondent) $86.9 \%$ is reported that their satisfaction is due to Benefit.

5. Availability of pharmaceutical: From the total of satisfied staff (213 respondent) $11.7 \%$ is reported that their satisfaction is due to availability of appropriate quantity of pharmaceutical.

6. Support from implementing NGO: From the total of satisfied staff (213 respondent) $12.2 \%$ is reported that their satisfaction is due to the support given by implementing NGO.

7. On time payment of salaries: From the total of satisfied staff (213 respondent) $8.5 \%$ is reported that their satisfaction is due to on time payment of salaries by implementing NGO.

8. Work load: No figure is obtained to show that satisfaction is due to this variable.

9. Supportive supervision: From the total of satisfied staff ( 213 respondent) $8.9 \%$ is reported that their satisfaction is due to supportive supervision by implementing NGO.

10. Other factors: on $2 \%$ of the satisfied staff mentioned that their satisfaction is due to other factor that is provision of training. 
Figure 4:-Factors Resulting Satisfaction

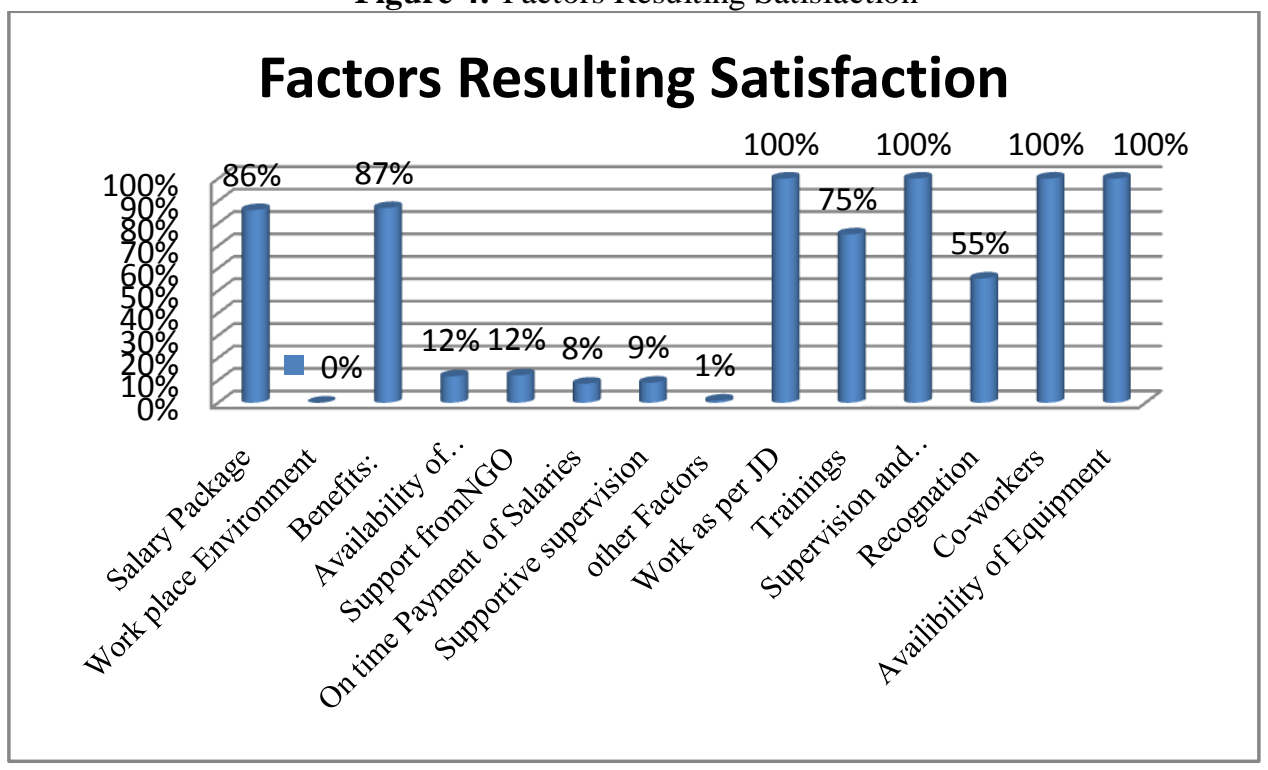

Meanwhile the satisfaction rate between the provinces are shown in the graph 4 below:

Figure 4:-Comparison of Satisfaction rate between the provinces

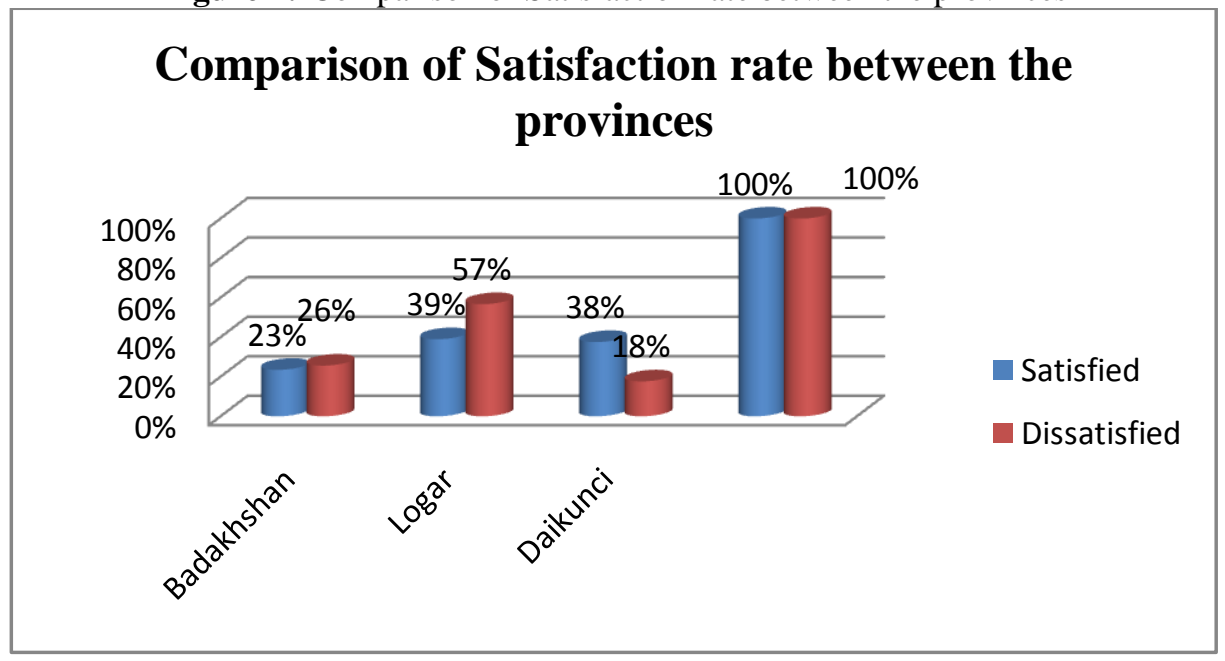

Other Findings:-

Work content:-

Overall the $100 \%$ of satisfied staff (213 Respondent) are reported that they know what are expected from them and $19.7 \%$ of them reported that job allow them to use their skills meanwhile from dissatisfied staff $96.2 \%$ reported that they do now know what are expected from them and $92.9 \%$ has mentioned that the job does not allow them to use their skills.

\section{Autonomy:-}

Overall the $100 \%$ of satisfied staff (213 Respondent) are reported that they have autonomy is their job while from dissatisfied staff (238 Respondent)96.6\% has mentioned that they have autonomy in their job.

\section{Work Demand:-}

Overall 100\% (451)participants reported that there is no unnecessary procedure in their job to take them away from their actual work and $98 \%$ of the respondent has mentioned that the entire tasks are as per their job description. 


\section{Capacity development:-}

In general $16 \%$ of the respondent has reported that their job provide them with adequate opportunities to learn new skills and the rest has mentioned contrary. The chi square test result $\left(\chi^{2}(1) 95.734, p<0.0001\right)$ show that those health workers that feel their job does not provide adequate opportunity are more likely to be dissatisfied than those who feel their job provide them with opportunity to learn new skill. Meanwhile $42.1 \%$ of the respondent reported that they participate in training and $57.9 \%$ that they are not.

The chi square test result $\left(\chi^{2}(1) 10.88, p<0.001\right)$ show that those health workers who participated in the training are more likely to be satisfied than those who did not participate in the trainings.

About the quality of the training; $42.1 \%$ of the total participants (451) reported that they participate in trainingwere satisfied with the quality and the same percentage have mentioned that the training were as per their need.

\section{Financial:-}

About the issue whether the payment covers the employee needs $1 \%$ has reported positively, $99 \%$ mentioned that the salary they receive is not covering their needs.

\section{Supervision and communication:-}

Overall $100 \%$ of the total respondents reported that they are supported by the assigned supervisor, they have access to supervisor, they receive regular feedback and their jobs are well explained to them.

\section{Motivation:-}

Overall $26.2 \%$ of the respondent reported that when they do good job they are recognized and when they do not perform their job they are punished and the rest $73.8 \%$ has mentioned that they are never recognized or punished.

\section{Co-worker:-}

Overall $100 \%$ of the staff stated that they have good relationship within the health facility with all the team.

\section{Others:-}

Overall $100 \%$ of the staff stated that they have necessary equipment and pharmaceutical to perform their duties and their work is meaningful for them moreover $70.1 \%$ of the respondent has mentioned that they condition of the health facility building is appropriate and the rest $29.9 \%$ has mentioned that the building is not appropriate.

\section{Discussion:-}

Job satisfaction is the attitudes and feelings people have about their job.It is an issue that affects the lives of all workers including health professionals and is also a factor that determines whether an employee will remain in a position or seek work elsewhere. Furthermore, job satisfaction can influence the quality of work produced.According to Ittner and Larcker (2003), employees who feel satisfied with their jobs provide higher levels of customer satisfaction and quality service delivery. In order to ensure quality health service delivery in Afghanistan we need to know the level of staff satisfaction, fill the gaps and ensure satisfaction. Ntseliseng, M. (2014) states that every Health Facility is expected to render quality and professional healthcare services and in order to do so, healthcare employees needs to be satisfied with their jobs. Therefore this study is made to identify Afghanistan Public health facilities staffs' satisfaction and Factors affecting the job satisfaction, the gaps within the human resource aspect of the health system and accordingly address them through sharing of the results with BPHS \& EPHS implementer and other stakeholders to acquire their attention in this important aspect of health system.

In this study, 52.8\% (238) of the total respondents reported that they are dissatisfied and $47.2 \%$ (213) respondents reported that they are satisfied. As per the analysis in general the factors resulting dissatisfaction includes low salary, low benefit, work load, no supportive supervision and other factors such as insecurity, no risk benefits for the staff, no required living facilities for delocalized staff, no recognition, no training in use of new medical equipment and insufficient professional trainings.Overall dissatisfaction among Health worker at public health facility in Afghanistan is a cause for concern, given that the factor of job satisfaction could have implications for the overall efficiency, effectiveness and quality health service delivery. Among these factors identified that results dissatisfaction;the most significant factors are low salary package, Low benefits, no supportive supervision, 
insufficient professional trainings and recognition which are consistent with other studies. In a study made in Pakistan on job satisfaction by Ramesh.k et al. (2013)shows that low salaries, lack of training opportunities, improper supervision and inadequate financial rewards were the factors for dissatisfaction; besides a study conducted in Tanzania also reported the poor job satisfaction in their health system due to lack of job description, poor rewards system, discouraging working environment and weak communications with the staff.Meanwhile this study is consistent with the study made on job satisfaction and its determinants among health workers in Jimma University Specialized Hospital, in Southwest Ethiopia where the satisfaction rate were low and the major reasons reported for their dissatisfaction were lack of motivation, inadequate salary, insufficient training opportunities and inadequate number of human resources. Beside this study is consistent with the study done in 2004 in Canada on community pharmacists in which the respondents reported that adequate staffing; increasing resources and salary were main factors for improving job satisfaction of pharmacists (AlemshetYami et al. 2011). Furthermore as per Yami (2011) a study was conducted in four states of America where opportunities for professional growth, recognition of accomplishments of assigned duties and realistic work load in relation to salary were suggested to be addressed to increase satisfaction of health professionals on their job.

Furthermore this study was designed to find out the rate for staff satisfaction and or dissatisfaction in Afghanistan public Health facilities. As such, it provides a snapshot of health worker perspectives at one point in time, and the causal relationships between satisfaction and performance cannot be further delineated in this study. Thus this study did not measure performance of health workers, so it is not clear how the reported factors relate to their actual performance. Such analyses will be important to policy maker and the health project implementers for whom performance is the most important outcome. Researchers have also posited that health worker satisfaction is clearly linked to workers' performance (Dolea C \& Adams O. 2005). Therefore more attention is needed for developing interventions and strategies that directly address the factors found to influence health service provider satisfaction and then to conducting rigorous intervention research to evaluate the effectiveness of these interventions on healthcare worker performance.

\section{Conclusion/Recommendation:-}

Job satisfaction of public health workers is an essential part for ensuring high quality service delivery. The finding of the study indicates low salary package, low benefits, no supportive supervision, insufficient professional trainings and recognition are rated of more important factors of dissatisfaction; thereforeinterventions should be carried out to increase levels of job satisfaction among public health professionals to obtain higher level of health worker satisfaction and accordingly ensure high quality service delivery and for this purpose following recommendation needs to be considered as the priority:

1. Revision of current salary package of health workers.

2. Consider risk allowances for staffs who are directly exposed to risks such as radiation and other chemical substances.

3. Consider sufficient hardship allowance for the staff who works in insecure areas or other remote areas.

4. The implementing organizations needs strengthen a supportive supervision using the different appropriate approaches.

5. Ensuring training opportunities for skill development of existing professional skills looks to raise health worker satisfaction. Therefore implementing NGOs needs to focus attention on this aspect of the health sector.

6. Having system of reward and punishment are linked with satisfaction level of the health workers, therefore system rewarding and punishment needs to be in place.

7. Continuous service evaluations and the monitoring of job satisfaction can be useful to determine various aspects of the services that necessitate improvement.

Tables and Figures:-

Table 1: List of regions and provinces of Afghanistan

Table 2: List of selected provinces

Table 3: List of selected district from selected provinces of Afghanistan

Table 4: Calculation of Study Participants

Table 5: Study work plan

Table 6: Case processing summary

Table 7: Satisfaction rate 
Table 8: Comparison of Satisfaction between Male and Female Figure 1. Staff Satisfaction rate

Figure 2. Comparison of Satisfaction between Male and Female Figure 3. Factors Resulting Dissatisfaction

Figure 4. Factors Resulting Satisfaction

Figure 5. Comparison of Satisfaction rate between the provinces

\section{References:-}

1. Timothy A. et al (2001) The Job Satisfaction-Job Performance Relationship

2. McKenna, E. (2012). Business Psychology and Organizational Behaviour A Student's Handbook. East Sussex, Psychology Press Ltd.

3. Mullins, L. J. (2005). Management and Organizational Behaviour. Essex Pearson Education Limited.

4. Ntseliseng, M. (2014). Job Satisfaction in the Healthcare Services in South Africa

5. David, H.P et al. (2010) Job satisfaction and motivation of health workers in public and private sectors.PMC. Human resource for health

6. AlemshetYami et al. (2011) Job Satisfaction and Its Determinants Among Health Workers in Jimma University Specialized Hospital, Southwest Ethiopia

7. Armstrong, M. (2013). Strategic Human Resource Management: A Guide to Action. 4th Ed. USA: Kogan Page Ltd.

8. Amos, T.L., Ristow, A., Ristow, L. \&Pearse, N.J. (2011). Human Resource Management. 3rd Ed. Entrepreneurship Series. Cape Town:JUTA

9. Linda, F. et al (2014) Job satisfaction and retention of health-care providers in Afghanistan and Malawi.PMC.Human Resource for health

10. Siddiqui, N. a\&khandakar, S. (2007). Patient satisfaction with health services in Bangladesh. Health Policy and Planning. 22(4), pp.263-73.

11. Newman, Karin, Maylor, Uvanney, and Chansarkar, Bal. (2001), The nurse retention, quality of care and patient satisfaction chain, International Journal of Health Care Quality Assurance 14, 2, 57-64.

12. Atkins, P. Mardeen, Marshall, Brenda Stevenson, and Javalgi, Rajshekhar G. (1996), Happy employees lead to loyal patients, Journal of Health Care Marketing 16, 4, 14-23.

13. Kammerlind, Peter, Dahlgaard, Jens J., and Rutberg, Hans (2004), Climate for improvement and the effects on performance in Swedish healthcare-a survey in the County Council of Ostergotland. Total Quality Management \& Business Excellence 15, 7, 909-924.

14. Joint Commission on Accreditation of Healthcare Organizations. (2005), Health care at the crossroads: Strategies for addressing the evolving nursing crisis. Chicago.

15. Katja, G et al. (2015) Working Atmosphere and Job Satisfaction of Health Care Staff in Kenya: An Exploratory Study. Hindawi Publishing Corporation. BioMed Research International

16. Ramesh Kumar et al. (2013) Job satisfaction among public health professionals working in public sector: a cross sectional study from Pakistan.Bio Med Central

17. Bailey RJ, Dal Poz M. Building the public health workforce to achieve health-related development goals: moving forward in collaboration. J Public Health Policy. 2010;31:494-497. doi: 10.1057/jphp.2010.34. [PubMed] [Cross Ref]

18. AMS (2010) Ministry of Public Health. Kabul, Afghanistan

19. Dolea C \& Adams O. (2005) Motivation of health care workers-review of theories and empirical evidence. Cahiers de SociologieetDemographieMedicale. 2005;45(1):135-136. [PubMed]

20. Ittner, C.D \&Larcker, D.F. (2003).Coming up short on nonfinancial performance measurement. Harvard Business Review, pp. 2-10.

21. Government of Ethiopia and the World Bank (2004). Health Sector Review. Ethiopian social sector studies. 1st Ed. Addis Ababa: Mega; 2004.

22. Leshabari.MT et al. (2008)Motivation of health care workers in Tanzania. Muhimbili National, P.32-37 